This is a preprint version of the article which has been published in the Journal of Land Use Policy. DOI: https://doi.org/10.1016/j.landusepol.2019.104359

\title{
A structured framework for 3D cadastral data validation - A case study for Victoria, Australia
}

\author{
Ali Asghari*, Mohsen Kalantari, Abbas Rajabifard \\ The Centre for Spatial Data Infrastructures and Land Administration, Department of Infrastructure Engineering, \\ The University of Melbourne, VIC 3010, Australia
}

\begin{abstract}
There are a wide variety of cadastral objects, ranging from simple 2D entities such as a land parcel, to complex 3D objects such as multistory/multi-owned buildings. The complex infrastructures development happening above and below the ground complicates the processes required for defining rights, restrictions and responsibilities in 3D (3D RRRs). Even in the current, predominantly, 3D analogue cadastral system which relies on 2D drawings and representations, defining 3D RRRs is still a complicated task. With the widespread use of 3D geospatial information technologies, it is increasingly becoming easy to realise and interpret a 3D digital cadastre system. As part of the process of transition from the 2D representation of cadastre towards a 3D digital cadastre, not only will 2D representations be replaced with $3 \mathrm{D}$ models, but the examination workflow and its principles will also need to be able to manage 3D models. Developing principles and validation rules is a critical requirement to guarantee that the diverse cadastral data is trustable and contains enough detail to define the spatial and legal extents of ownership. This paper proposes a structured framework to define validation rules for 3D cadastral models. The paper's methodology utilises a case study approach where a plan examination process in Victoria, Australia has been analysed to investigate the principles of examining cadastral plans, and further expanded on for validating 3D digital plans. The paper concludes with a discussion on the implications of the proposed 3D validation rules and proposes future research within the topic of $3 \mathrm{D}$ cadastral data validation.
\end{abstract}

Keywords: Land management, 3D digital cadastre, Cadastral data, ePlan, Validation, Victoria

\section{Introduction}

The increasing need for land in urban environments results in the ever-growing development of complex urban infrastructures both above and below ground. 3D geospatial information technologies facilitate mapping and modelling built environments like high-rise buildings and subways for many purposes, including managing RRRs. The technologies and methods to acquire, process and analyse 3D data are developed enough for cadastral applications (Ross, 2010, Khoo, 2012). These technologies provide opportunities to upgrade from a $2 \mathrm{D}$ representation of cadastre to a $3 \mathrm{D}$ representation. Researchers now accept the 3D digital cadastre as an effective technical means to support the administration of space (Guo et al., 2013). Several national and international studies on 3D cadastral development have been carried out (Jaljolie et al., 2018, Eriksson and Jansson, 2010, Stoter and van Oosterom, 2005, Stoter et al., 2013, Stoter and van Oosterom, 2006, Karki et al., 2010a, Renzhong et al., 2011, AIEN et al., 2012). Despite all the developments, there are still many steps towards a fundamental solution for a 3D cadastre, including the validation of 3D data.

Validation is the process of checking data for possible errors according to the standards and pre-defined rules, before the data is used for a system or application. Through the process of data validation, the characteristics of data quality such as integrity, consistency, completeness and correctness are examined (Wagner et al., 2013). The integrity of any cadastral system is dependent on the quality of its data and is only guaranteed by valid cadastral data. For defining a reliable and transparent extent of ownership, cadastral data needs to meet the requirements of validity. Currently, subdivision plans are supported by 2D-based representations to delimit 3D ownership rights, which become intrinsically complex in structurally and functionally complicated multistory developments (Atazadeh et al., 2017). The problems arising from using 2D plans are extensively investigated in the scope of 3D digital cadastres. There are limitations recognised in the current 2D-based practice of representing and communicating 
both spatial and ownership information within built environments (Atazadeh et al., 2017). The majority of these limitations stem from the ineffective management and ambiguous representation of complex legal definitions within built environments (Rajabifard et al., 2018).

From a validation and examination perspective, the problem is, current ad hoc 2D principles are not capable of ensuring a trustable and definitive physical and legal definition of 3D property objects in built environments and as a consequence, they will fail to validate 3D digital data. The diversity of possible shapes and geometries in space, as well as differently defined ownerships for property objects, makes principles and validation rules more complicated in a 3D cadastral context compared to a $2 \mathrm{D}$ cadastre (Karki et al., 2010b). On the one hand, the nature of 3D digital data requires new spatial principles based on new mathematical methods. For example, checking the misclosure of a 3D enclosed parcel to avoid creating gap and overlap is not possible with 2D misclosure methods. On the other hand, specifying ownership to a volume (3D) as opposed to a surface (2D), mandate new regulatory constraints to define 3D RRRs.

The primary objectives of this study are to investigate the principles of examining cadastral plans, identifying the challenges in the principles in relation to a 3D representation of RRRs and extending these in order to check the validity of the 3D digital representation. This paper has been organised in the following way. First, the recent studies on 3D validation are reviewed. Subsequently, the Victorian cadastral system, ePlan Protocol, and a discussion on the existing plan examination practice in Victoria, Australia will be given, followed by identifying the challenges in the current examination for $3 \mathrm{D}$ representation. It will then go on to the development of a framework for validation of 3D RRRs. Finally, the paper provides discussion and concluding remarks, as well as highlighting future trends within the topic of 3D cadastral data validation.

\section{An overview of recent studies on 3D validation}

Validation takes on different meanings depending upon the context and circumstances of the application. In recent studies, "3D validation" and "3D validation rules" are the terminologies used to check the quality of 3D data (Karki et al., 2010b, Karki et al., 2013, Thompson and Van Oosterom, 2012, Gröger and Plümer, 2011, OOSTEROM, 2012, Shojaei et al., 2017). Some of the cadastral validation rules in previous studies originate from other applications or contexts. For example, to examine both geometric and semantic aspects of 3D geospatial data in a 3D city model, a number of principles were developed by (Gröger and Plümer, 2011). Examination tests such as the closedness test, connectedness test, inner-outer check and the orientation check were also developed by Kazar et al. (2008) to check the validity of 3D geometric primitives like simple solids.

The principles used in these studies underpinned some validation rules for checking the validity of 3D objects in the cadastre context. For example, a rigid axiomatic definition of a 3D parcel and its relationship with abutting parcels were modified by Thompson and Van Oosterom (2011a) based on (Gröger and Plümer, 2011) to reflect the cadastral requirements. They also developed a set of geometric axioms for the Land Administration Domain Model (LADM) to ensure the validity of individual parcels defined by 2D primitives, 3D primitives and a combination of the two like "liminal" parcels (2D parcels adjoining 3D parcels) (Thompson and Van Oosterom, 2012).

3D cadastral data validation can also be considered from three aspects: 1) validity and reliability of single 3D parcels; 2) Validity of the relationship of 3D parcels neighbouring other 3D parcels. 3) validity of 2D parcels abutting 3D parcels. According to these aspects, different situations involving 3D geometries for cadastre were listed by (Karki et al., 2010b). They proposed different validation rule's classes as requirements for validating $3 \mathrm{D}$ cadastral data based on the similarity of conditions as follows:

- Internal validity of 3D parcels 
- Surface or base parcel

- Relationships with other parcels

- Unique geometrical situations

- Further processing on the geometry

- Entry-level validations

They also propounded the concepts of "face strings" and "liminal" parcels for the issues relating to the mixture of 2D and 3D parcels existing in virtually all cadastres worldwide.

Shojaei et al. (2017) attempted to develop four geometrical validation rules existing in the ePlan Protocol, the electronic plan lodgment and examination system in Australia, for checking 3D objects. However, the diversity of cadastral situations leading to the development of different principles is beyond that of the ePlan classification for validation rules, and needs a comprehensive classification.

Few researchers have examined the topological spatial relationships as one of the most critical factors for 3D cadastral data validation and representation ( $\mathrm{Fu}$ et al., 2018). Reasonable description and identification of all possible relations may ensure the consistency of the spatial representations of 3D parcels and thus prove their legitimacy (Zhao et al., 2012). Various topological relations amongst 3D cadastral objects like touch, disjoint or even intersection were described by Zhao et al. (2012). They described a new method to validate the relationship among 3D parcels with a focus on touch scenario. A validation function for a 3D topological structure was implemented by Brugman et al. (2011). They developed a series of topological validation tests based on a 3-level formal definition of a valid structure. Fu et al. (2018) investigated the unique characteristics of the topological relations in 3D cadastral data and proposed a classification method for 3D cadastral topological relations.

Collectively, these studies provide important insights into the 3D validation concept, but there are still some research gaps in the recent literature as follows:

- Most 3D cadastral validation rules are defined from a 3D city model perspective. However, research on 3D cadastral validation is quite different from the 3D city model validation. For example, the concept of two-manifold is not a necessary criterion for 3D cadastral parcels (Thompson and van Oosterom, 2011b).

- The main validation rules rarely follow the regulations and standards inside a cadastre system. Firstly, principles and validation rules need to be developed based on a structured framework following the regulations and standards of a cadastre system, and then, they should be localised to be compatible with cadastral law in each jurisdiction.

- There is a wide range of 3D models using different approaches to represent and manage the spatial dimension of 3D RRRs like pure legal, pure physical and integrated methods (Atazadeh and Kalantari, 2016). However, regarding the validation of these models, the only focus has been on legal boundaries in recent studies and far too little attention has been paid to the integrated methods.

To develop a framework for 3D cadastral data validation based on a cadastre system, we use a case study approach. In the next section, we will present the cadastral system and the examination process of cadastral plans in Victoria, Australia.

\section{Victorian cadastral system}

\subsection{Background}

In Australia, a consistent system of land titling known as the Torrens Titling System is followed by all the states (Toms et al., 1986). Nevertheless, a state government undertakes the responsibility for the administration of land, including the surveying and subsequent titling (Dalrymple et al., 2003). While 
the essence of land administration is identical in all Australian jurisdiction, the realisation and interpretation of that are different in each state, which includes law and regulation governing land, systems and workflows. As a result, the state land administration and cadastral systems vary in detail, bringing about discrepancies in semantics and data structures amongst different states (Cumerford, 2010). To provide a consistent system for land surveyors and users of this system and in line with modernisation of cadastre, the Intergovernmental Committee on Surveying and Mapping (ICSM) commenced the development of standards in 2003 to support electronic submission and exchange of cadastral data through the "ePlan" (electronic plan) frame. In 2009, ICSM endorsed ePlan as an agreed conceptual national data model of a cadastral survey that meets the requirements of all Australian jurisdictions (Aien et al., 2014). Several states in Australia including Queensland, New South Wales and Victoria as well as Singapore Land Authority, have adopted the ePlan for their cadastral systems. The main aim of ePlan is to replace 2D paper and PDF plans with digital files based on national standards. 2D ePlan has provided several services such as validation, visualisation and digital data download as well as digital plan examination in Victoria since 2013 (Figure 1).

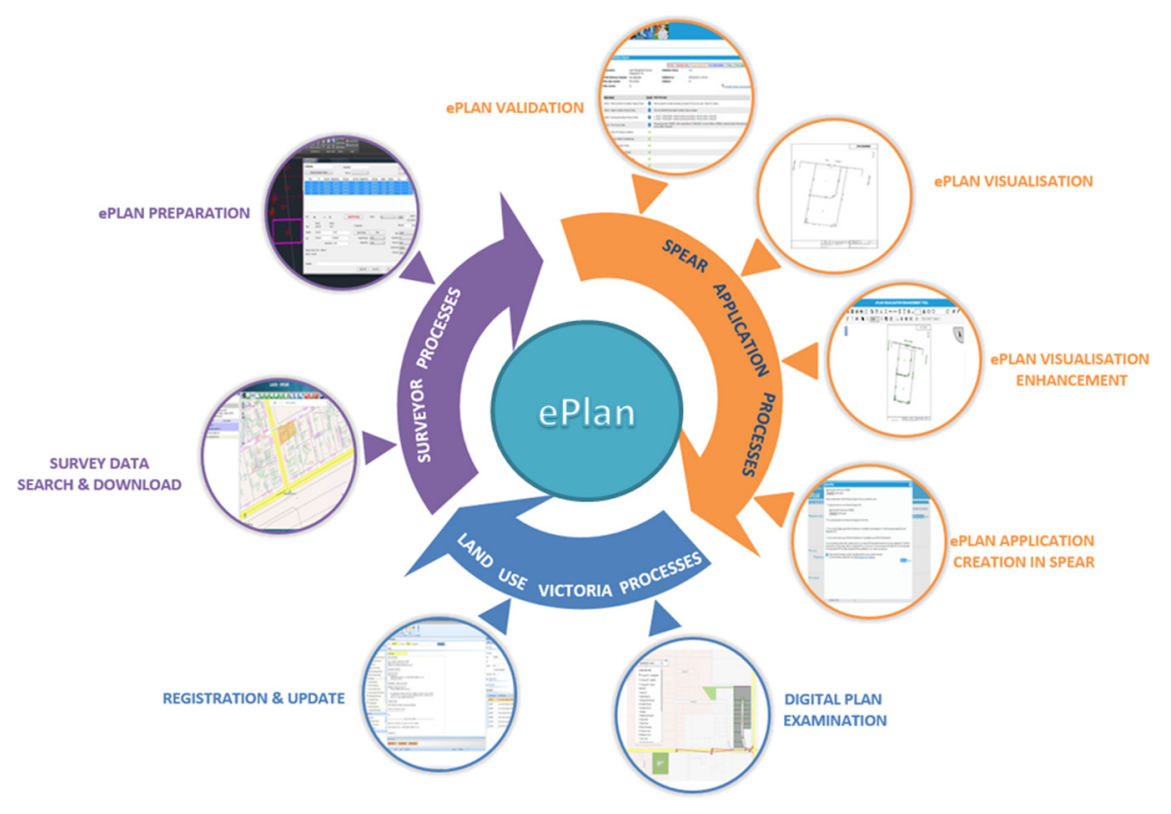

Figure 1 A quick view of ePlan services (Source: www.spear.land.vic.gov.au)

\subsection{Cadastral plan examination in Victoria}

In this section, the examination process, which is the terminology for validation in Victoria, will be discussed. To fully understand the process, first, we need to get familiar with some definitions and types of cadastral data used in this process.

\subsubsection{Different types of cadastral plans}

Section 3 of the Subdivision Act 1988 (Victorian Government, 2011) defines three types of plans:

- Subdivision

- Consolidation

- Creation, variation or removal of an easement or restriction

A plan of subdivision allows splitting the land parcel into two or more new land parcels. In this study, instead of using "plan of subdivision", the short term "plan" is used. Different properties including land parcels (e.g. lots, roads, reserves or common property) or buildings (e.g. single-story building, townhouse or multistory buildings) can be represented in two types of plans, let us say 2D and 3D. There are also two different methods of cadastral plan creation, analogue (PDF, paper image) and digital (ePlan). In this paper, the terminologies "2D plan" and "3D plan" refer to the analogue types of a plan 
This is a preprint version of the article which has been published in the Journal of Land Use Policy. DOI: https://doi.org/10.1016/j.landusepol.2019.104359

of subdivision as described later; otherwise, the terminologies "2D digital plan" or "3D digital plan" will be used to address the digital type of cadastral plans.

\section{- 2D plan (2D floor plan without cross section)}

A 2D plan represents all the properties of land parcels, as well as all those buildings that do not have any change of height or depth. This type of plan only represents the 2D boundary of ownership, and it does not include any 3D representation such as cross-section. 3D data such as depth limitation is represented as a textual information and other spatial information (e.g. geometry) of a 2D parcel are represented through a diagram sheet (Figure 2).
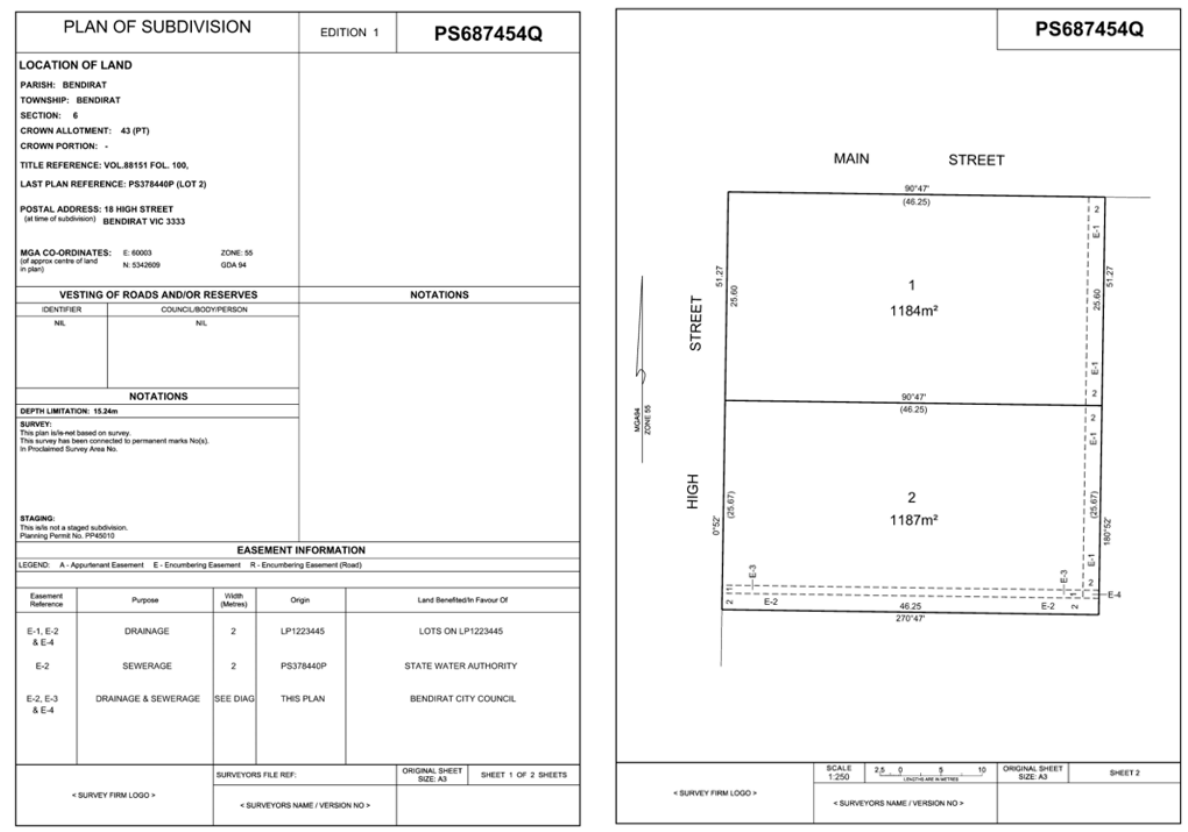

Figure 2 An example of a $2 D$ plan

\section{- 3D plan (2D floor plan with cross section)}

A 3D plan represents both vertical and horizontal information of property. The vertical information is represented through cross-section(s), where the objects are located above or below each other or when there is a limitation to height/depth of a property. The main difference between the $3 \mathrm{D}$ plan and a $2 \mathrm{D}$ plan is using the cross-section (Figure 3). 


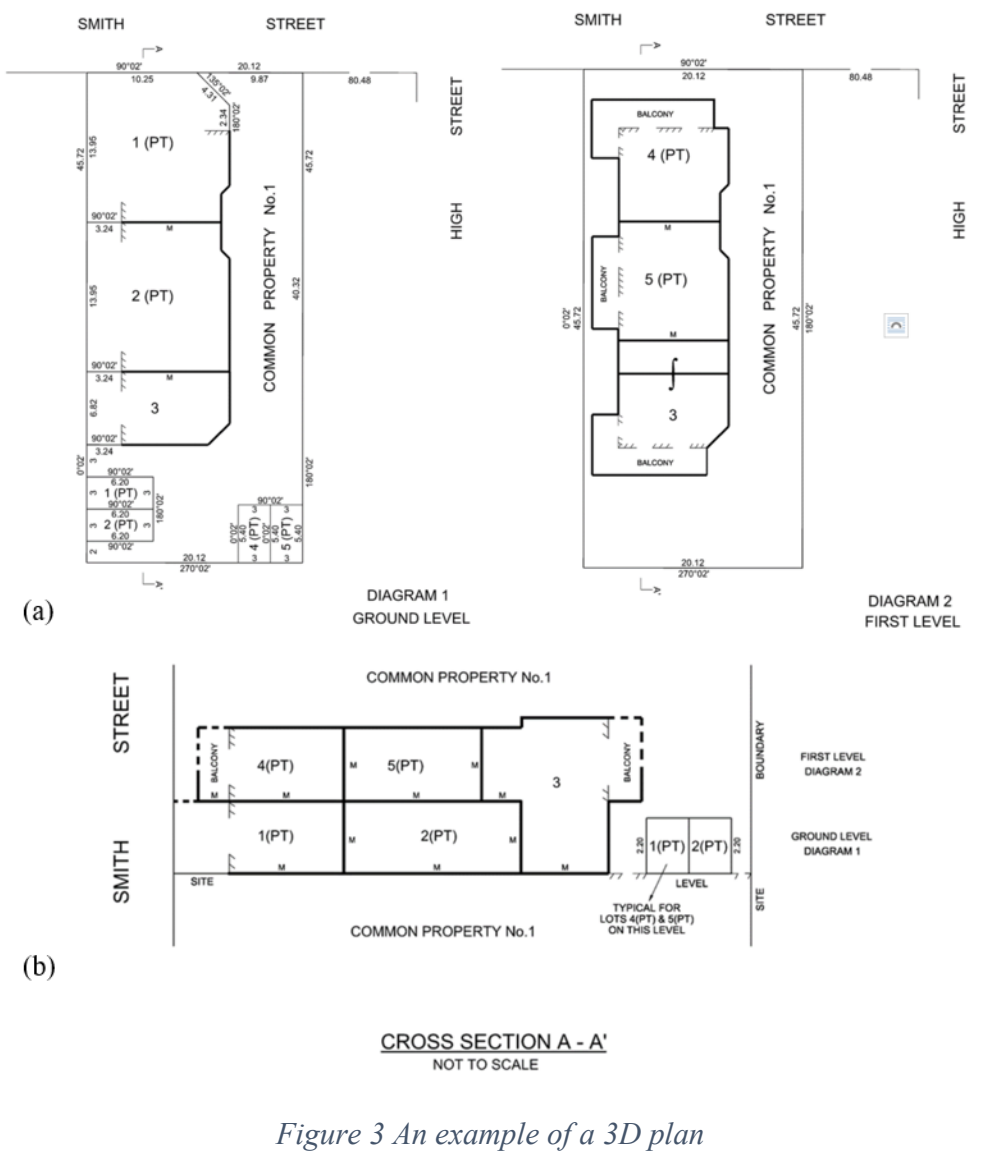

\subsubsection{Examination principles}

The examination principles can be divided into 3 categories:

\subsubsection{Regulatory Checks}

Regulatory principles look at the notation of 2D and 3D plans to support the requirements of cadastre. For example, the address of a parcel must be correctly captured (Shojaei et al., 2017). Notations usually represent the textual information, and communicate the information of different spatial components of a plan. These notations provide information such as the location of the land, the location of building boundaries or depth limitation. The Spatial information represented in diagram sheet and the textual information notated through face sheet needs to be consistent and coincident. Regulatory principles are utilised to check the validity of both textual and spatial information represented by notations.

\subsection{Non-spatial Regulatory Checks}

Non-spatial regulatory checks include examining administrative information, such as if easements drawn on the plan have valid purposes, the name of signatory surveyor is present, and the postal address of the subject land is provided.

\subsection{Spatial Regulatory Checks}

Spatial regulatory checks are referred to those types of notations communicating the information of spatial elements of plans like lot, easement, common property, depth limitation and building boundaries. For example, if a boundary is defined by reference to a/part of building, the plan must specify the type and location of the boundary through notation. Spatial regulatory checks regarding boundaries follow two regulations based on (Subdivision (Registrar's Requirements) Regulations, 2011):

- Regulation 10 sets out the use of buildings to define boundaries in a plan. 
This is a preprint version of the article which has been published in the Journal of Land Use Policy. DOI: https://doi.org/10.1016/j.landusepol.2019.104359

- Regulation 11 sets out the methods of showing boundaries.

The regulations above provide some crucial footnotes that need to be considered while checking a plan:

- Reg 11(12): States that all boundaries must be dimensioned except for:

- Existing natural boundaries

- Existing building boundaries

- New building boundaries

- Reg 11(3): The default method of identifying boundaries defined by buildings is a thick continuous line.

- Reg 11(1): Non-building boundaries (e.g. using the fence to separate properties) are to be shown as a thin continuous line.

- Reg 10(3): To have a clear and definitive interpretation of ownership, plans defining boundaries by buildings must specify the boundary as one or more of the following:

- Interior face

- Median (floor and ceiling)

- Median (wall, window, door, balustrade)

- Exterior face

- Any other location that can be described

Some of these regulatory checks have been implemented as validation rules in the ePlan system. The table below lists some of these validation rules in ePlan.

\begin{tabular}{|l|l|}
\hline No & Regulatory Checks in ePlan \\
\hline $\mathbf{0 0 5}$ & Easement Purpose Exists \\
\hline $\mathbf{0 0 6}$ & Owners Corporation Limitation Exists \\
\hline $\mathbf{0 0 9}$ & Primary Parcel Address Exists \\
\hline $\mathbf{0 1 1}$ & Reference Mark Completeness \\
\hline $\mathbf{0 2 1}$ & Plan Number Format \\
\hline $\mathbf{0 2 3}$ & Surveyor Registration Number \\
\hline $\mathbf{0 3 4}$ & Depth Limitation Manual Check \\
\hline $\mathbf{0 3 5}$ & LGA and Parish Exist \\
\hline $\mathbf{0 4 0}$ & Address in Vicmap Address \\
\hline $\mathbf{0 4 1}$ & Title Reference in VOTS \\
\hline $\mathbf{0 5 1}$ & Easement Purpose Manual Check \\
\hline
\end{tabular}

Table 1 An overview of textual and spatial regulatory checks in ePlan

\subsubsection{Internal spatial consistency checks}

The internal spatial consistency checks assure single cadastral objects are correctly defined according to the regulations and standards. The examination and its principles are based on the regulations and standards like (Surveying (Cadastral Surveys) Regulations, 2005), (Subdivision (Registrar's Requirements) Regulations, 2011) and (Subdivision (Procedures) Regulations, 2000). 
This is a preprint version of the article which has been published in the Journal of Land Use Policy. DOI: https://doi.org/10.1016/j.landusepol.2019.104359

According to the (Surveying (Cadastral Surveys) Regulations, 2005), all parcels in plans must define a spatial extent (boundary) using fully dimensioned lines (i.e. having bearing and distance). However, no dimension is required where building structure is used as whole or part of a spatial extent (Figure 4).

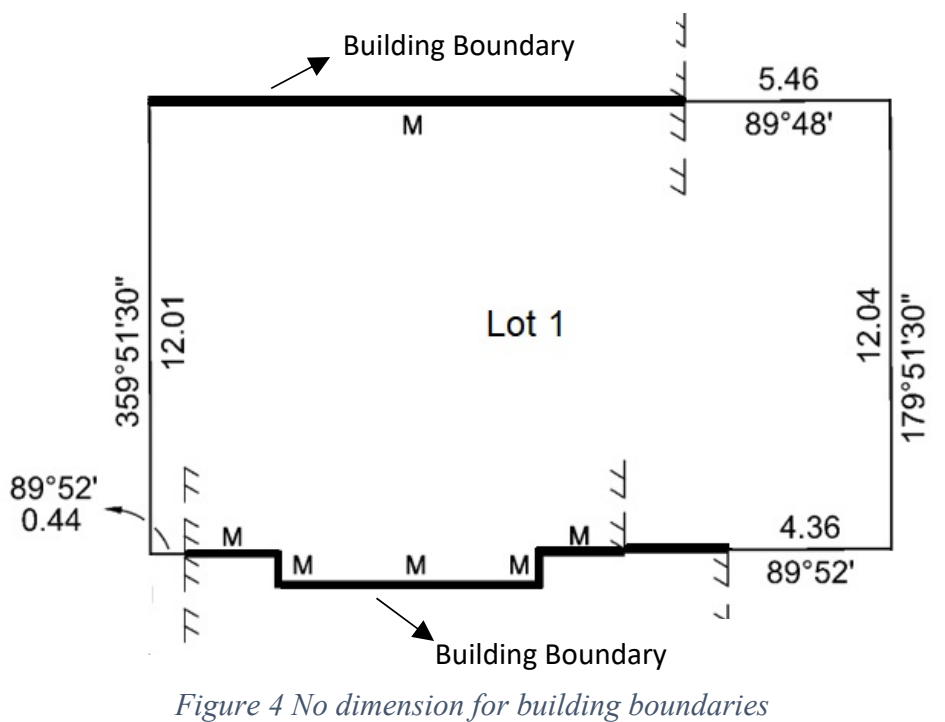

All parcels in plans are also expected to be "close" within a threshold. The length of the misclosure vector should be less than 15 millimetres +100 PPM of the perimeter (Figure 5). Consequently, created and extinguished lots, stage lots, roads and reserves must contain area measurement. The area must match the calculated area from the parcel dimensions within the allowable tolerance. The area is not required for parcels containing ambulatory boundaries like irregular lines. This specific type of general boundaries is defined based on observing the movement of dynamic natural features such as coastlines, river borders and water creeks (Atazadeh et al., 2017).

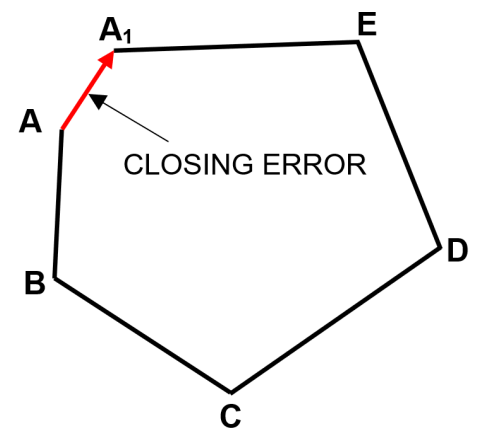

Figure 5 Misclosure Error in 2D Parcel

\subsubsection{External spatial consistency checks}

While the internal spatial consistency checks assure every individual cadastral object is correctly defined, the external spatial consistency checks make sure that the objects are correctly positioned in relation to a datum (local or geographic) and their neighbouring cadastral objects.

\subsection{Primary Parcel Connection}

Primary parcel (includes lots, roads, reserves and common properties) connection refers to the abuttals used to connect the subdivision to the surrounding land. Accordingly, primary parcels must be connected to one of the following in the order of preference:

- Road alignment intersection

- Bend in a road alignment

- Crown parcel 
- Natural boundary

As can be seen in Figure 6, if there is no fixed length to the "parcel A" to keep it fixed, various perceptions about the exact location of this parcel can be implied. This constraint is only applied to the base parcel for 2D/3D plan examination. The plan also needs to be connected to the required number of permanent marks, primary cadastral marks and reference marks according to the regulations (Surveying (Cadastral Surveys) Regulations, 2005).

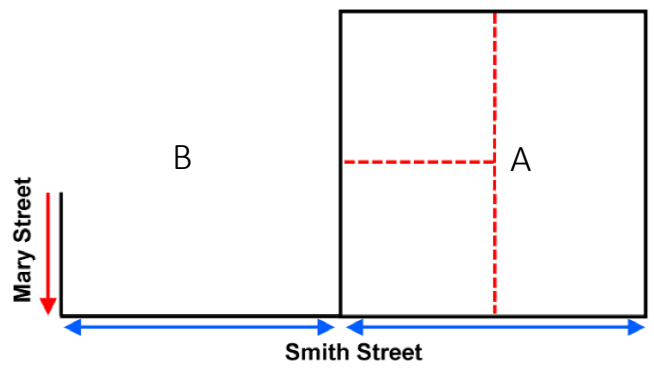

Figure 6 Example of primary parcel connection (Source: ePlan handbook)

\subsection{Secondary Interest Connection}

Secondary interests must be positioned in relation to primary parcels. The relation is defined by either a shared corner with a primary parcel (Case E-1 in Figure 7) or a set of measurements (bearing \& distance) to a primary parcel corner (Case E-2 and E-3 in Figure 7).

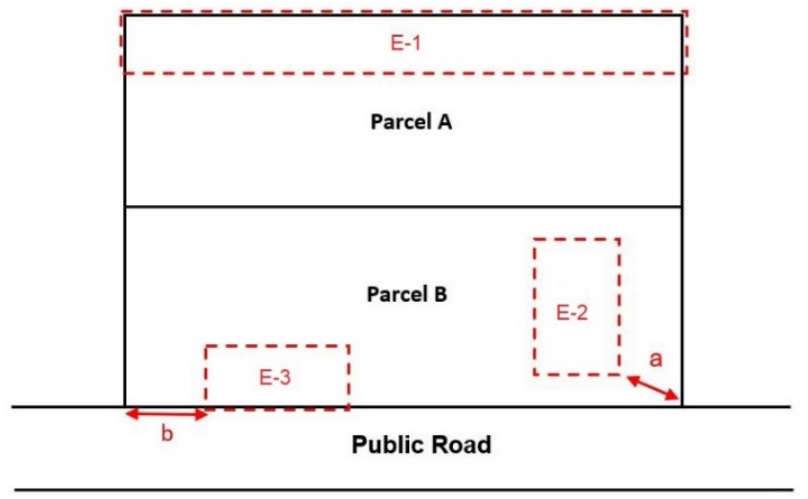

Figure 7 Example of easement connection

\subsection{Spatial Gap and Overlap checks in RRRs}

For the prevention of any gap or overlap, the outer boundary of created primary parcels must be shared or coincident with the outer boundary of extinguished parcels. Besides, these created parcels are not allowed to overlap or create a gap between parcels (Figure 8). The total area of created parcels is equal to the area of the extinguished parcel. 
This is a preprint version of the article which has been published in the Journal of Land Use Policy. DOI: https://doi.org/10.1016/j.landusepol.2019.104359

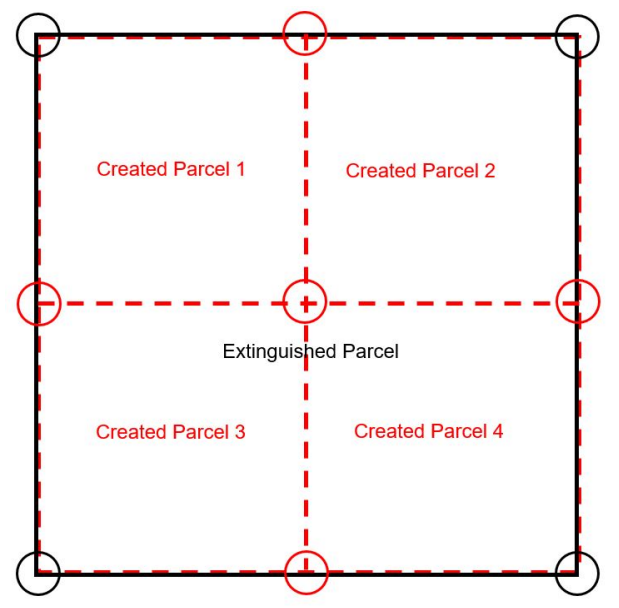

Figure 8 Title boundary consistency in $2 D$ plan

From a legal perspective, overlapping is equivalent to encroachment, which can result in legal disputes (Figure 9).

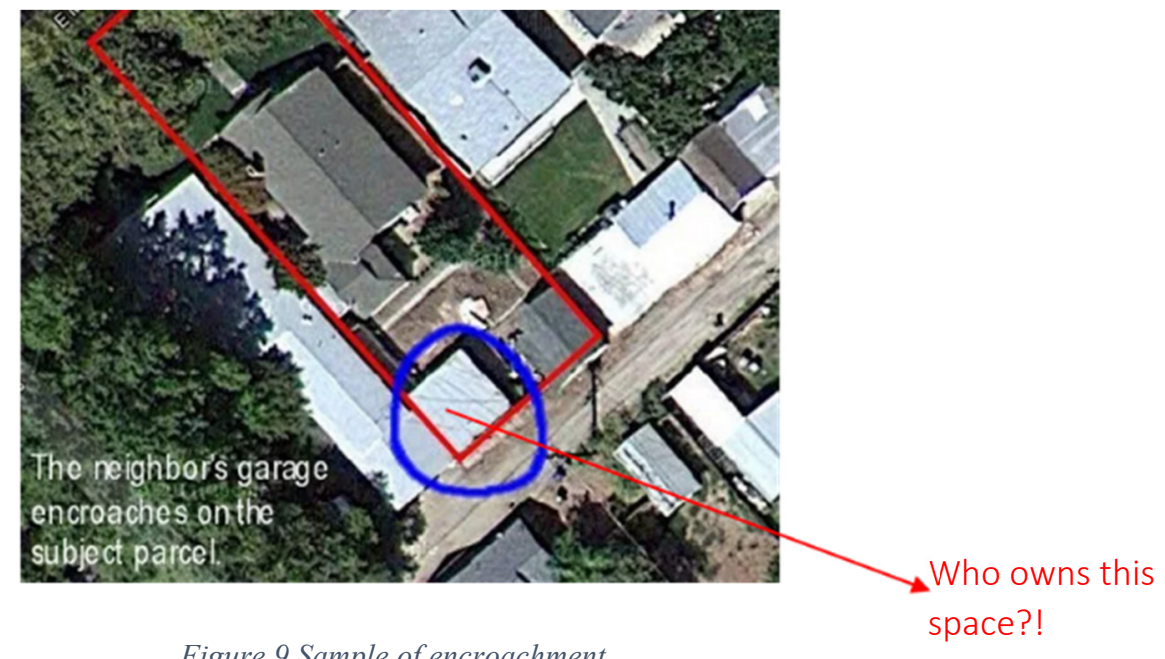

Figure 9 Sample of encroachment

To prevent any encroachment from happening, primary parcels must not overlap each other. However, secondary interests which provide some benefits or pose some restrictions on primary parcels can spatially intersect primary parcels and secondary interests. As one of the spatial regulatory checks, when two or more easements intersect or overlap, one unique easement identifier is to be shown in each portion of the easement on the plan diagram (Figure 10). 
This is a preprint version of the article which has been published in the Journal of Land Use Policy. DOI: https://doi.org/10.1016/j.landusepol.2019.104359

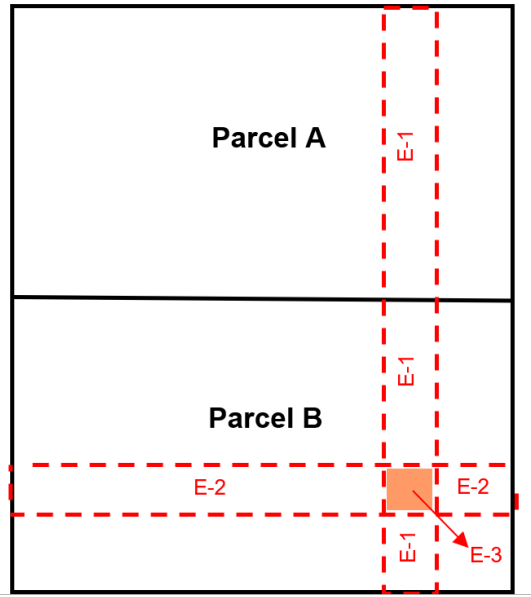

Figure 10 An example of easements intersection

Some of the spatial validation rules implemented in the ePlan system are listed in table 2.

\begin{tabular}{|l|l|}
\hline No & Geometrical Validation Rule \\
\hline $\mathbf{0 0 4}$ & Parcel Geometry Exists \\
\hline $\mathbf{0 5 2}$ & Easement Fixing \\
\hline $\mathbf{0 6 3}$ & Parcel Area \\
\hline $\mathbf{0 6 8}$ & Parcel Dimensions Exist \\
\hline $\mathbf{0 6 9}$ & Parcel Geometry Closure \\
\hline $\mathbf{0 7 1}$ & Parcel Observations Closure \\
\hline $\mathbf{0 7 2}$ & Title Boundary Consistency \\
\hline $\mathbf{0 7 3}$ & Title Connection \\
\hline $\mathbf{0 7 4}$ & Survey Marks Connection \\
\hline $\mathbf{0 8 4}$ & Restriction Fixing \\
\hline $\mathbf{1 0 1}$ & CoordGeom for Abuttals and Connections \\
\hline $\mathbf{1 0 6}$ & Easement Width \\
\hline $\mathbf{1 1 7}$ & Overlapping Parcels \\
\hline & \\
\hline
\end{tabular}

Table 2 An overview of spatial examination principles in ePLan

\subsection{Current examination practice challenges}

Through the ePlan system in Victoria, 2D digital plans go through a partially automated validation process. However, the examination of 3D plans is still a manual and somewhat challenging process when it comes to the interpretation of the vertical information. The challenges are highlighted below:

- Checking the regulatory constraints through notations is time-consuming, especially for a multistory high-rise building. Figure 11 represents a snapshot of checking consistency between 2D floor plans and cross-sections for a two-level building. Checking this thorough examination for a multistory development would be too arduous. 


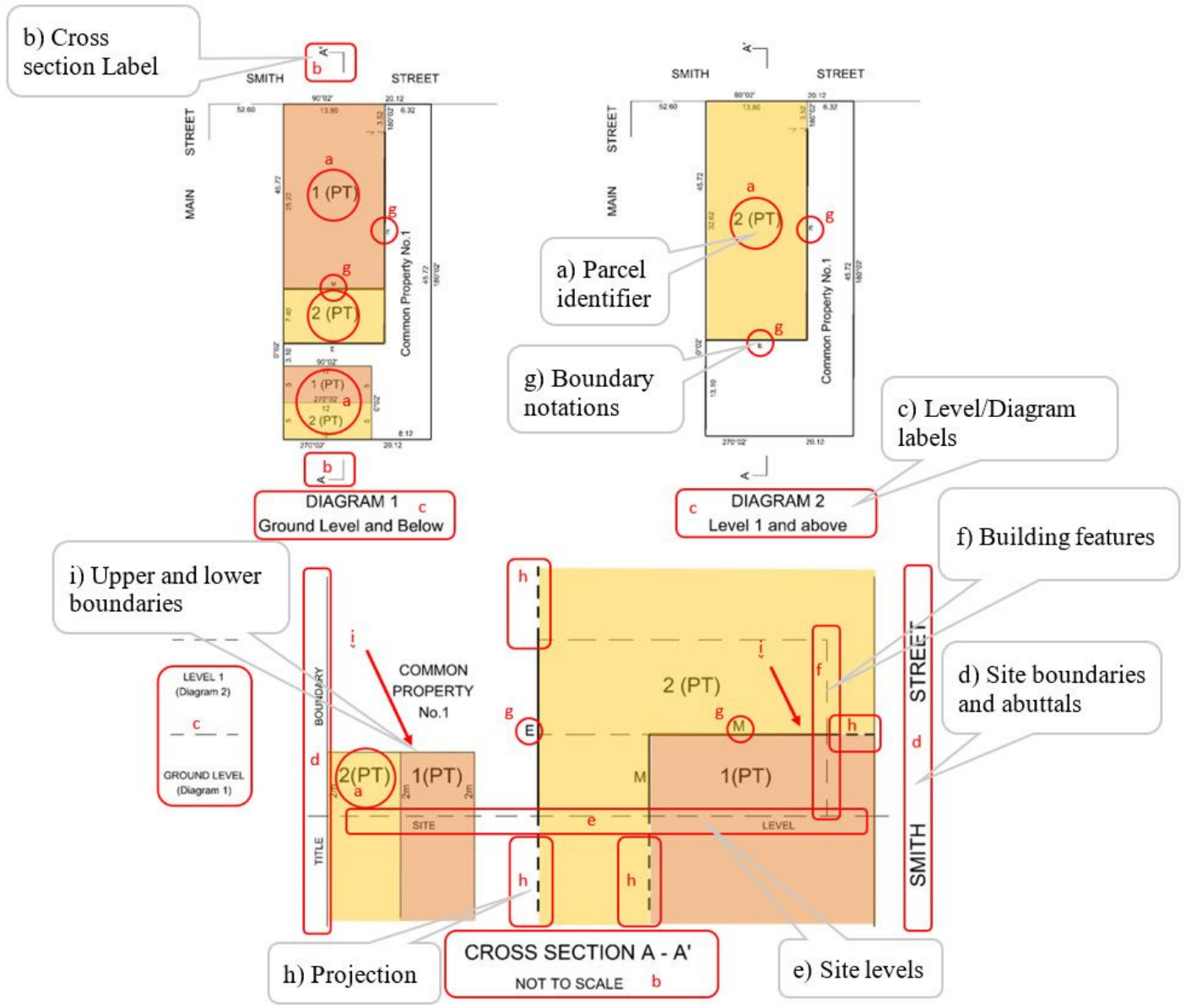

Figure 11 A snapshot of what must be checked in a 2D floor plan and cross section

- As can be seen in Figure 11, defining vertical and horizontal building boundaries (e.g. interior face, Median, exterior or other location) is still ambiguous and dependent on the notations in the plans.

- Recognizing the changes in the height of upper and lower boundaries (steps) (noted $b$ in Figure 11 ) is still hard and time-consuming for the examiners.

- Cross-sections are not sufficiently informative about the vertical dimension of a building and contain succinct information about the horizontal and vertical boundaries. As can be seen in Figure 11, there is no dimension used in the cross-section to provide spatial information for the third dimension.

- There might be misunderstanding of the interpretation of projections in cross-sections (noted $\mathrm{h}$ in Figure 11).

- Multiple pages of cross-sections are required to communicate vertical information of all 3D RRR spaces within a multistory building (Figure 12). Examination of such a large number of plans imposes a considerable amount of time and perspicuity and is still error-prone. 


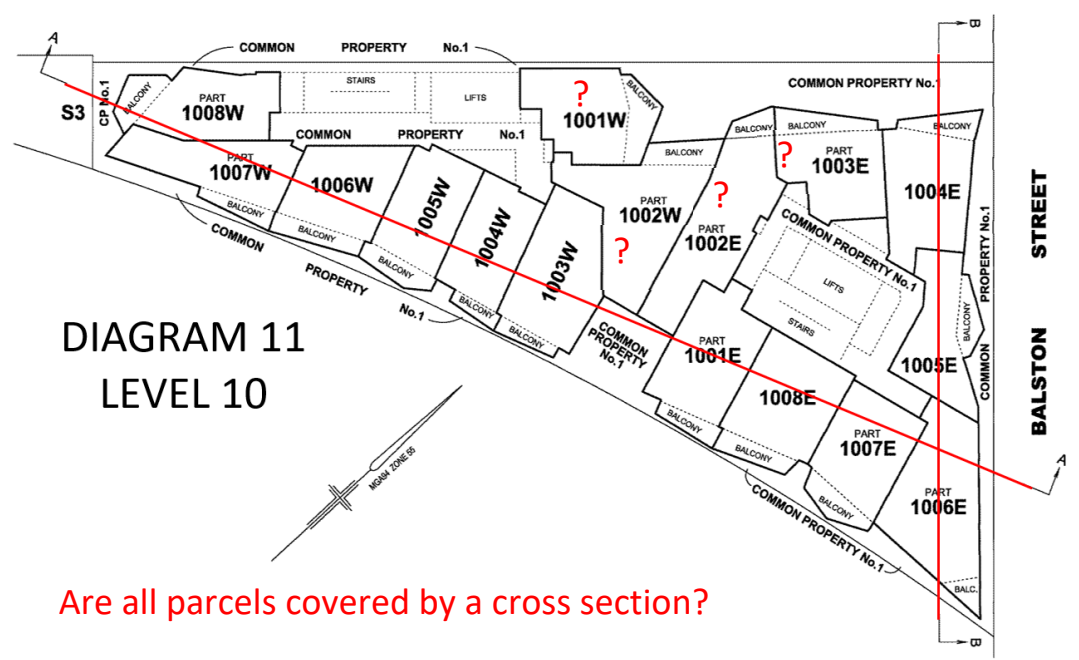

Figure 12 Using several cross sections to interpret the vertical information

\section{Conceptual principles for 3D digital plan examination}

The legal and physical objects in 3D plans can be stored, visualised and queried in a 3D digital system (Figure 13). However, to check the validity of the 3D digital plan, not only a 3D model but also a set of 3D principles defining the spatial and legal integrity of legal boundaries as well as volumetric legal spaces are necessary. In this section, we adopt and extend the current framework for the examination of plans to address the requirements for 3D checks.

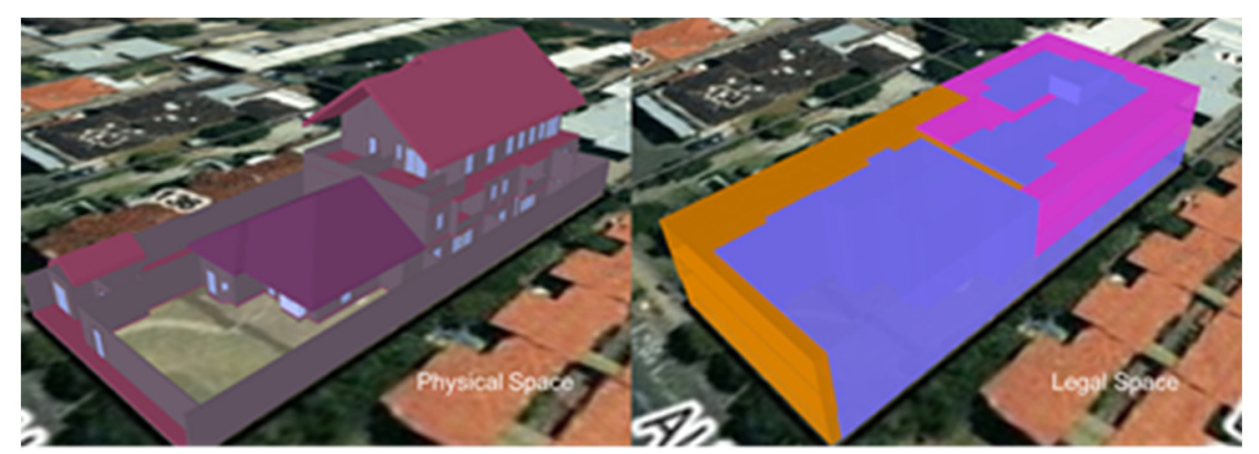

Figure 13 A snapshot of Land Use Victoria 3D ePlan prototype

\subsection{Regulatory checks in 3D}

In both 2D and 3D digital plans, the plan notations are transformed from textual data, that are detached from the spatial data into attributes of the spatial data. For example, in 3D digital plans, the information of depth or airspace limitation can be embedded into cadastral objects and ultimately represented visually in 3D. Thus, storing this information in 3D is expected to raise a few extra changes (Karki et al., 2010b). Regulatory checks in 3D need some minimal modifications to be applied to the 3D model (Shojaei, Olfat et al. 2017). The only challenge here is to find out what type of 3D regulatory checks can be possibly checked by human operation, and which ones can be automatically evaluated. 


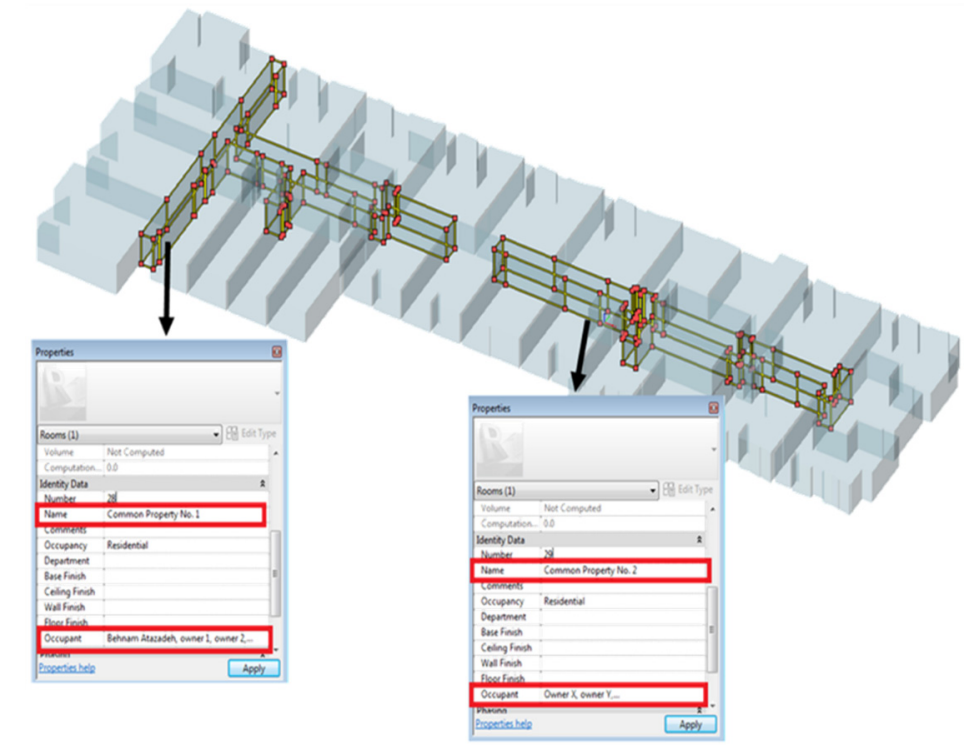

Figure 14 Textual information embedded in a 3D model (Source:(Atazadeh, 2017))

\subsection{Internal spatial consistency in 3D}

A 3D model can represent both the legal and physical dimensions of property objects and can store the quantitative information such as area, height, perimeter and volume of complex 3D objects. Not only the horizontal information but also the vertical information can be represented through a 3D model. (Figure 15). However, only a 3D model with a valid geometry can guarantee the correctness of this information. Hence, geometric correctness is a decisive factor for the quality and integrity of a 3D cadastre (Shojaei et al., 2017).

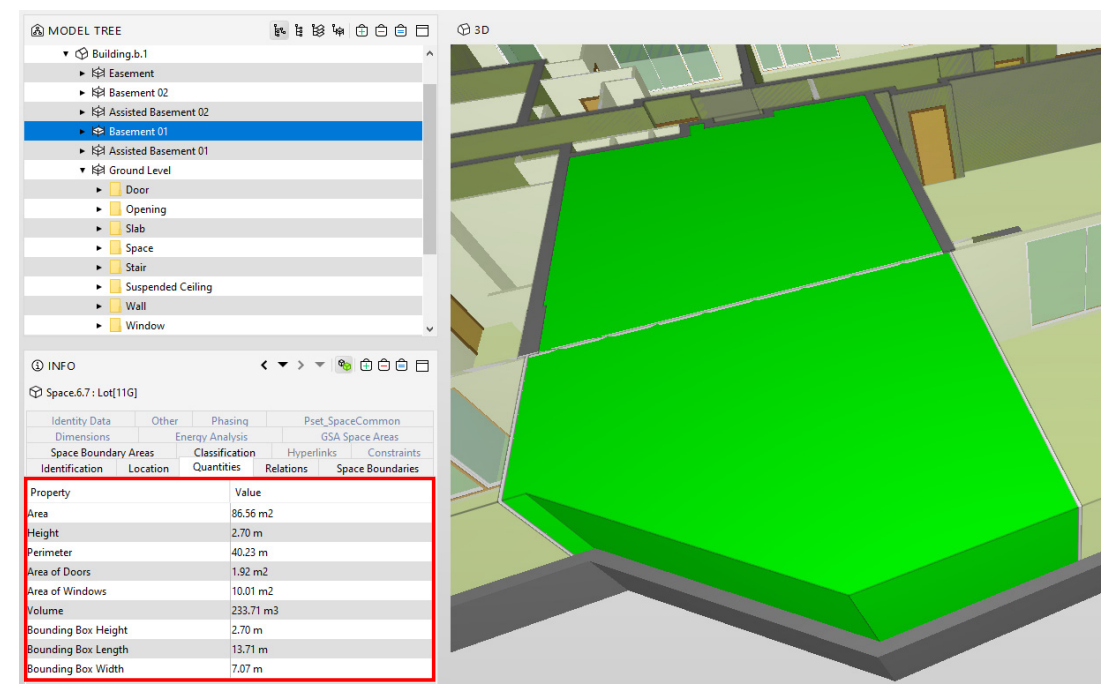

Figure 15 Presenting quantitative information of a 3 D object (lot)

A 3D object consists of vertices, edges and faces topologically. Before the faces of a 3D object are created, the duplication of vertices, as well as the self -intersection of edges, need to be checked. In the next step, the faces that make up a 3D object should be planar within a given threshold (Thompson and Van Oosterom, 2011a) which means that all vertices in a face should be in the same plane (Shojaei et al., 2017). In the case of extreme failure, due to different interpretation, various scenarios can happen so that the interior of the 3D parcel might not be legally definable (Figure 16). 

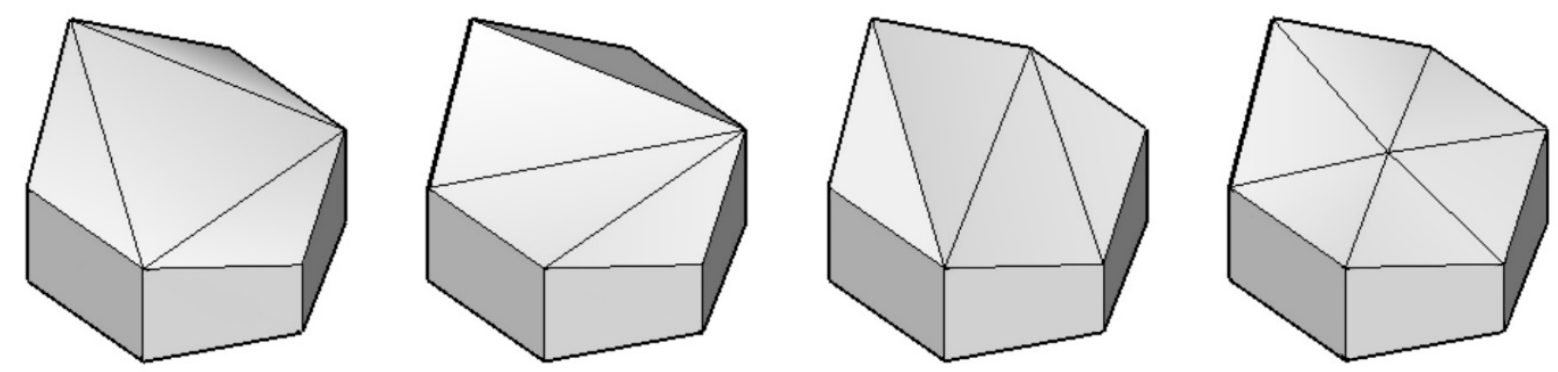

Figure 16 Different scenarios for a 3D parcel with non-planar face (Source: http://www.formz.com/)

\section{- The watertight concept in different 3D situations}

After 3D objects with valid faces are created, they need to be geometrically closed or "watertight" (Figure 17). This rule is required to avoid any misclosure in creating 3D objects (Shojaei et al., 2017). When a 3D object does not have any gap, it is considered watertight which refers to a 3D object with the capability of holding water without any holes, cracks or missing faces (Karki et al., 2010b).
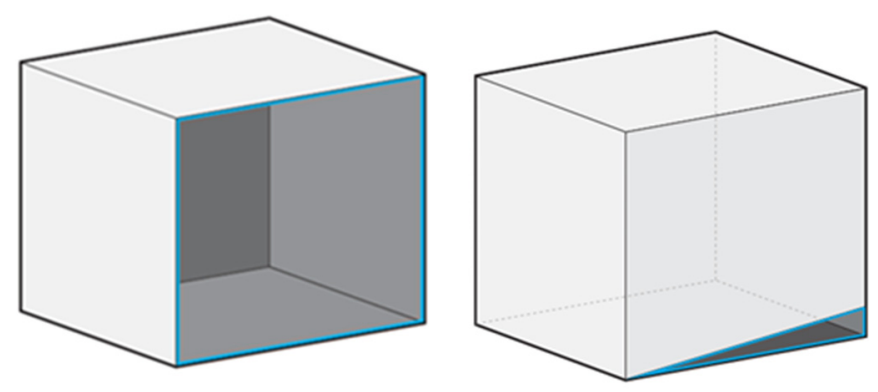

Figure 17 Two non-watertight 3D samples; a) missing face b) the gap in the surface.

It is critical to know that there is a difference between the 3D physical object itself and the legal space related to this object (Stoter et al., 2013). The watertight concept is not always considered for both the physical and legal dimensions of property objects represented by 3D models. In some situations, this validation rule might be applied only to the legal space of a 3D parcel, not necessarily to the physical space. For example, the physical boundary of a balcony is not necessarily watertight, while its legal boundary defining the ownership extent must be geometrically closed (Figure 18). However, legal spaces like the ownership defined in a lot mainly surrounded by physical structures like floor, wall and ceiling.

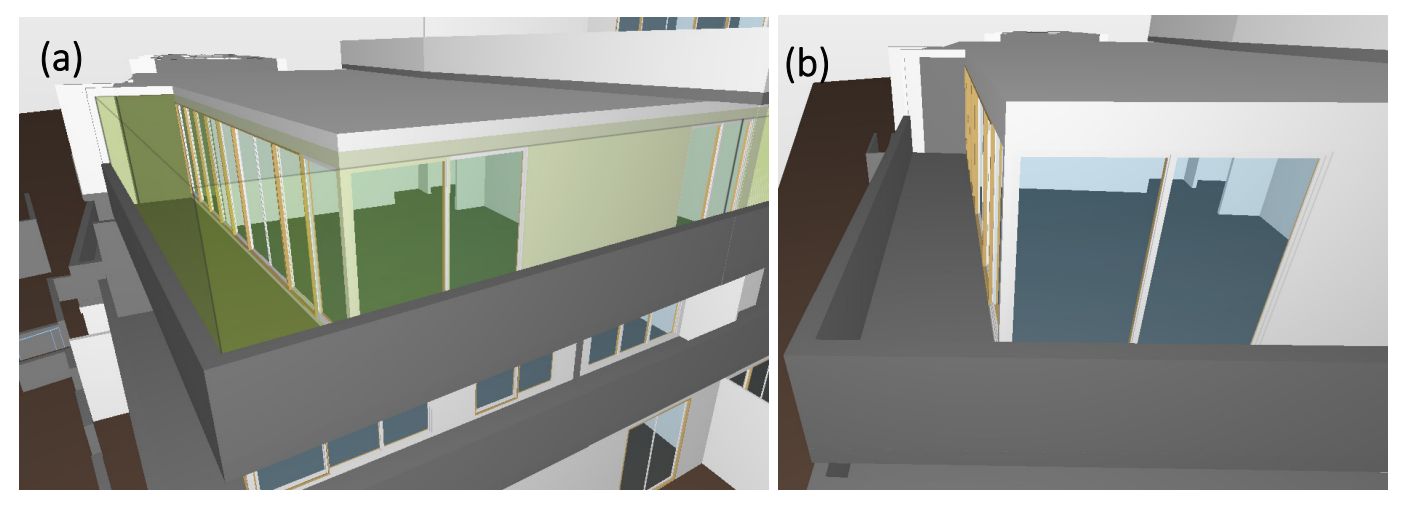

Figure 18 Two representation of (a) legal space (watertight), (b) physical boundary (non-watertight)

A 3D parcel can have various configurations that do not adhere to the watertight concept. A 3D parcel can be a 2D parcel with unbounded ownership (Figure 19a), a 2D parcel bounded from the bottom because of a depth limitation (Figure 19b), a 2D parcel bounded from the top because of the airspace 
This is a preprint version of the article which has been published in the Journal of Land Use Policy. DOI: https://doi.org/10.1016/j.landusepol.2019.104359

limitation (Figure 19c), or a 3D parcel enclosing 3D ownership space (Figure 19d). Although the 2D boundary of ownership (polygon) in cases a, b and c must be closed, since a 3D column of ownership is defined in these cases, the extent of volumetric legal space is not fully closed.
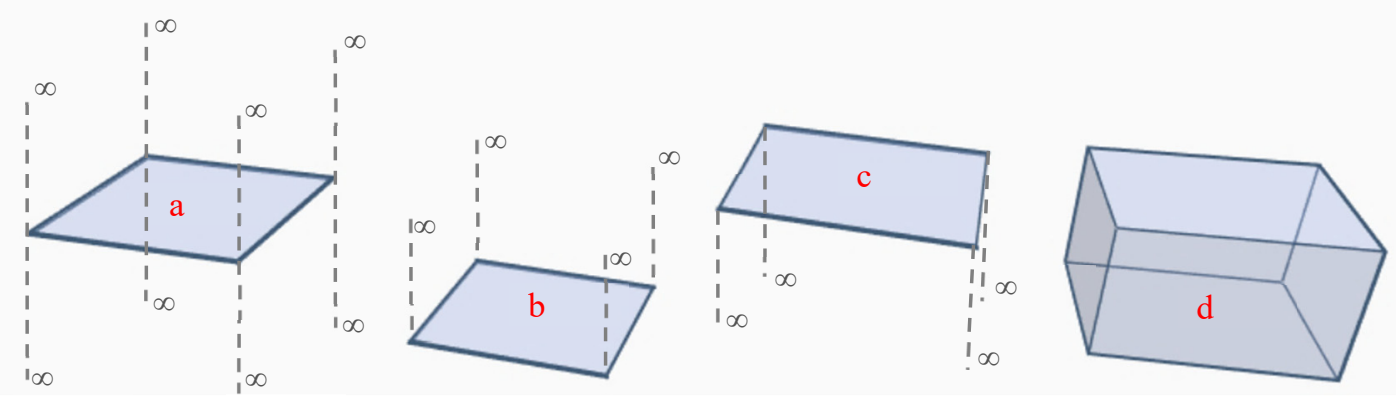

Figure 19 The schematic representation of ownership scenarios

The misclosure of a 3D parcel geometry can be analysed through a consistency approach using Euler's formula. According to Ericson (2004), to check the consistency of 3D objects, they are mandated to be 2-manifold objects. Two-manifold objects are not allowed to have self-intersections, holes or gaps in their faces (Gröger and Plümer, 2011). However, as can be seen in Figure 20, the definition of a 3D cadastral parcel may have nodes, edges, or faces repeated within a single parcel that makes a 3D cadastral parcel to be non-manifold (Thompson and van Oosterom, 2011b). Thus, to cover these cadastral objects, other algorithms and methods need to be developed. One such method is using mesh and triangulation algorithms.
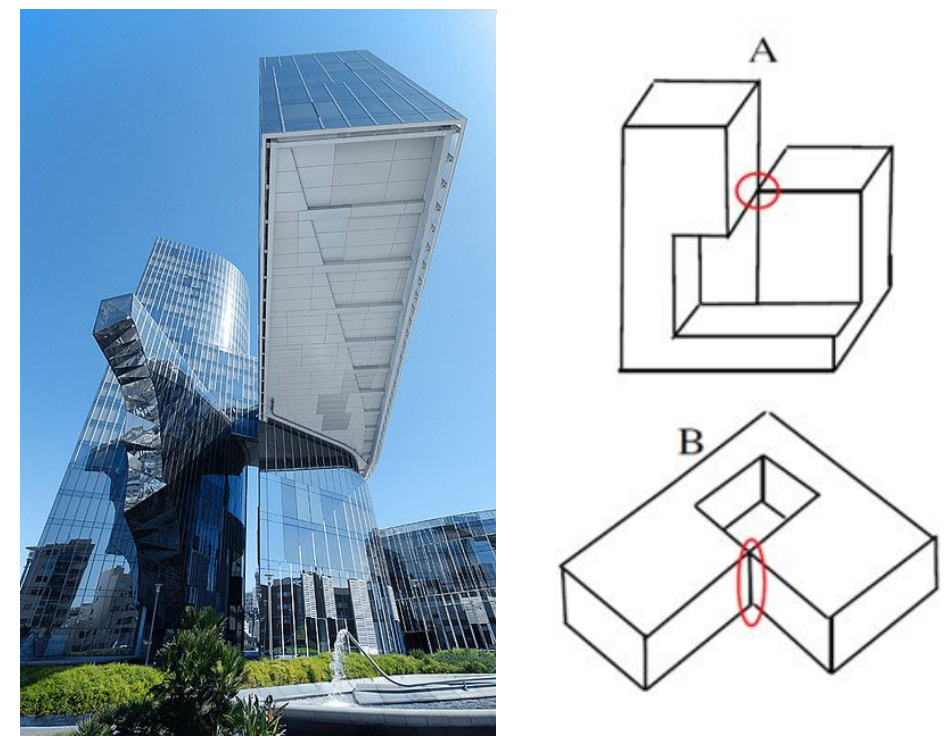

Figure 20 Non-manifold 3 D objects in cadastre

\subsection{External spatial consistency and connectivity in 3D}

\subsubsection{Primary parcel connection in 3D}

The spatial position of the 3D object in 3D digital plans needs to be positioned in space in relation to a local or geographic datum. The definition of primary parcel connection in 3D is dependent on how a volumetric lot is created. Based on (Karki et al., 2013), two methods can be considered to create a volumetric lot:

- Excised from an existing 3D column (Figure 21a)

- Created as a 3D lot on a 2D parcel (Figure 21b) 
In addition to the methods mentioned above, another approach is taken by LADM discussing that all 2D parcels are 3D columns of space above and below the ground surface with no defined top or bottom (Thompson and van Oosterom, 2011b) (Figure 19a).

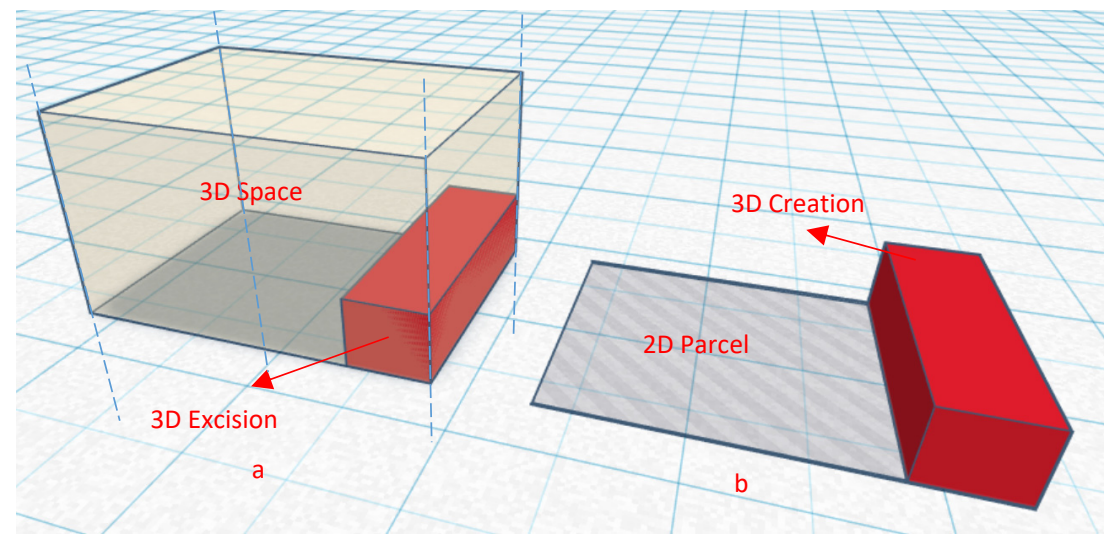

Figure 21 a) Excision of volumetric space, b) creation of a volumetric lot (Source: (Karki et al., 2010b))

In a real-world situation, all cases can be observed. However, the statement of validation rules for each one can be different. Although survey information is used to construct a 3D cadastral database, the structure chosen will rely on the view taken in this regard. For the first case, the title can be connected to surveying marks, so a concept like "face string" in LADM can be considered, and a multistory building for each level needs to be checked by these surveying marks. For example, what is seen in Figure 22 can be a multistory building, and a' is a survey mark. Each corner of this building needs to be connected to the survey mark for each level. A bearing and distance from a, b, c and d are required to a', b', c' and d' respectively.

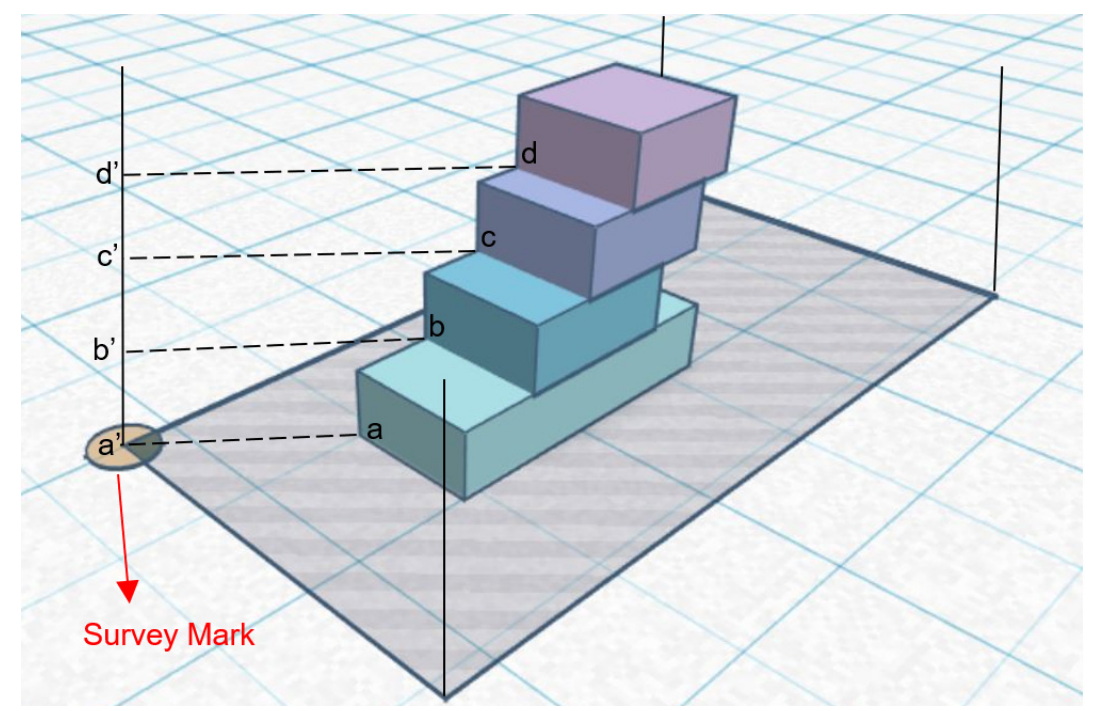

Figure 22 Proposed title connection to survey marks for 3D volumetric space

In the second case, the same method for 2D plans can be applied. If it is made sure that the 2D base lot is connected to surrounding land, a 3D volume which is going to be created through 2D parcel will be fixed. In this case, the Queensland approach can be followed to mandate that all 3D land parcels must exist within the bounds of a base lot (Karki et al., 2013).

\subsubsection{Primary parcel accessibility}

Accessibility constraints should be considered to check the connectivity of all lots in a 3D digital plan to the outside world. Firstly, any privately owned or occupied lot must be connected to space outside 
This is a preprint version of the article which has been published in the Journal of Land Use Policy. DOI: https://doi.org/10.1016/j.landusepol.2019.104359

through the common property to get accessibility. Secondly, any common property cannot be completely enclosed by a private parcel (Karki et al., 2013). For example, CP1 in Figure 23 is an invalid $3 \mathrm{D}$ object because it is surrounded by lot A. Since lot A is connected to the outside world through CP2 and it is accessible, CP2 represents a valid 3D object. The exact position of all parcels, including common property, must be defined in 3D for this check.

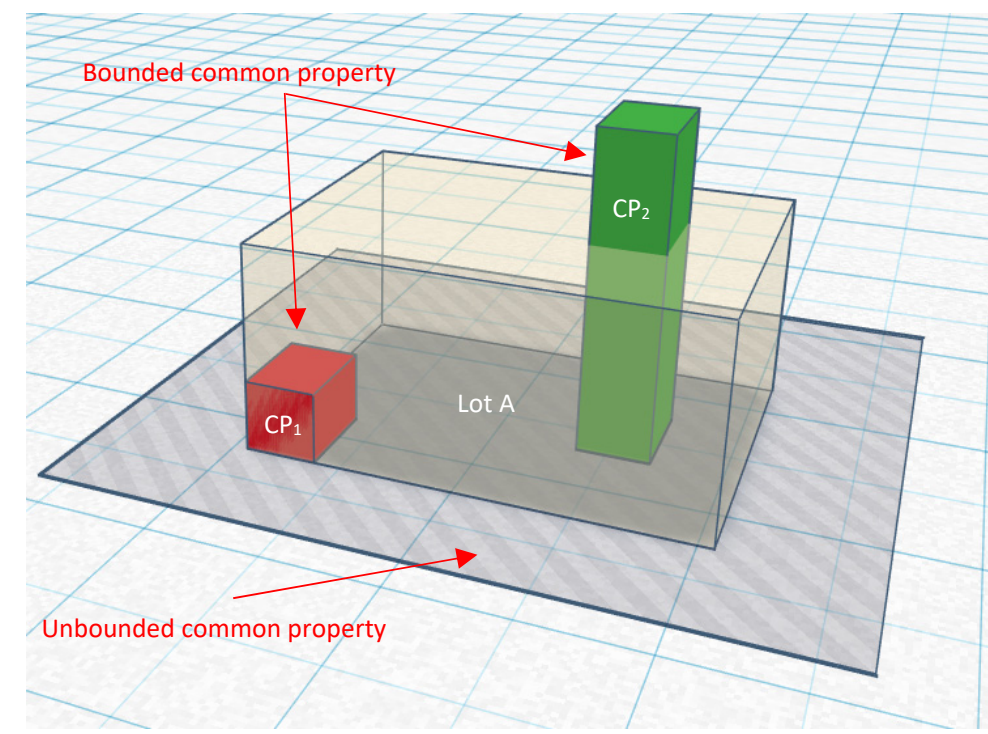

Figure 23 Two samples of valid and invalid bounded common properties (Source: (Karki et al., 2013))

\subsubsection{Secondary interest connection in 3D}

Secondary interests like easement or restriction in $3 \mathrm{D}$ are represented through volumetric objects. These $3 \mathrm{D}$ volumetric objects need to be positioned in relation to primary parcels. The relation is defined by either shared vertices or edges with a primary parcel (Case E-1 in Figure 24) or a set of measurements (bearing \& distance) to a primary parcel corner (Case E-2 and E-3 in Figure 24). The topological relationships like intersection can be utilised for checking the secondary interest connection in 3D cadastre. This is an exception in having an acceptable clash between two 3D volumetric objects.

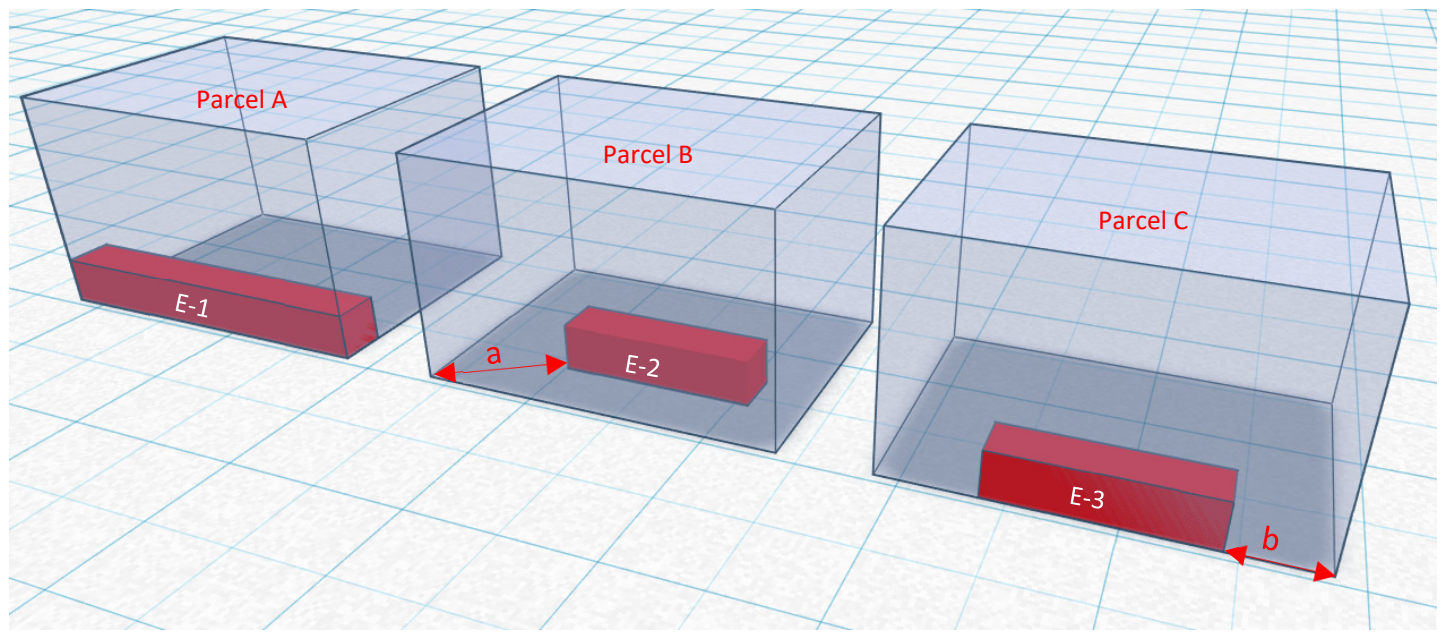

Figure 24 Example of easement connection in $3 D$

\subsubsection{Checking gap and overlap in 3D RRRs}

In a full 3D cadastre, the 3D space is subdivided into volumes (or 3D parcels) partitioning the 3D space without incision/gaps and collisions/overlaps (Stoter and Salzmann, 2003). In a 3D digital plan, the whole space of the extinguished (cancelled) parcel(s) must be occupied by the volume of created parcels 

Policy. DOI: https://doi.org/10.1016/j.landusepol.2019.104359

(Shojaei et al., 2017). Thus, after partitioning the space, the ownership(s) should be allocated to each space and volume consistency should be checked. Volume consistency checks the consistency between the volume of the created parcels and the extinguished parcels. For example, the sum of the created volumes must be the same as the volume of the extinguished parcels with an acceptable threshold in volume calculation (Figure 25).

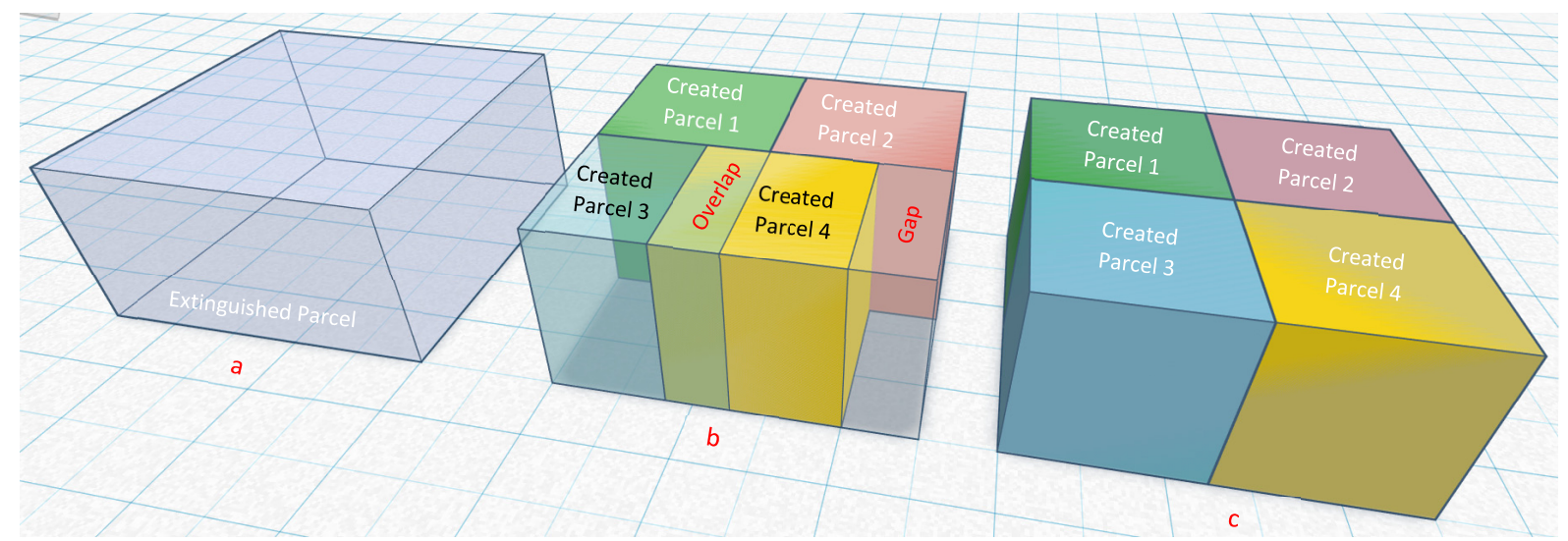

Figure 25 Title Boundary Consistency in 3D; a) Extinguished Parcel, b) Incorrect Subdivision, c) Correct Subdivision

In real 3D cadastre, 3D parcels contain both physical boundaries as well as legal spaces. To check the volume consistency, the definition of boundaries and volume spaces will influence the situation of ownership and also volume calculation. Shojaei et al. (2017) used a mathematical method developed by Zhang and Chen (2001) to calculate the volume of 3D cadastral objects. However, they only considered the legal spaces in their study to simplify the volume calculation. The different approach of defining building boundaries can influence defining ownership, and similarly, this can influence volume consistency.

As space cannot be occupied by more than one object, any clash between primary parcels is banned (Figure 26). Since the intersected space cannot be owned by two owners, any intersection between primary parcels is an invalid topological relationship. However, in real 3D cadastre, we may face some acceptable exceptions of clashes. Secondary interests can spatially intersect with primary parcels (Atazadeh, 2017). For example, an easement with the drainage or sewerage purposes can go through a lot, which is an acceptable collision (Figure 27). It is also allowed for two secondary interests having an intersection.

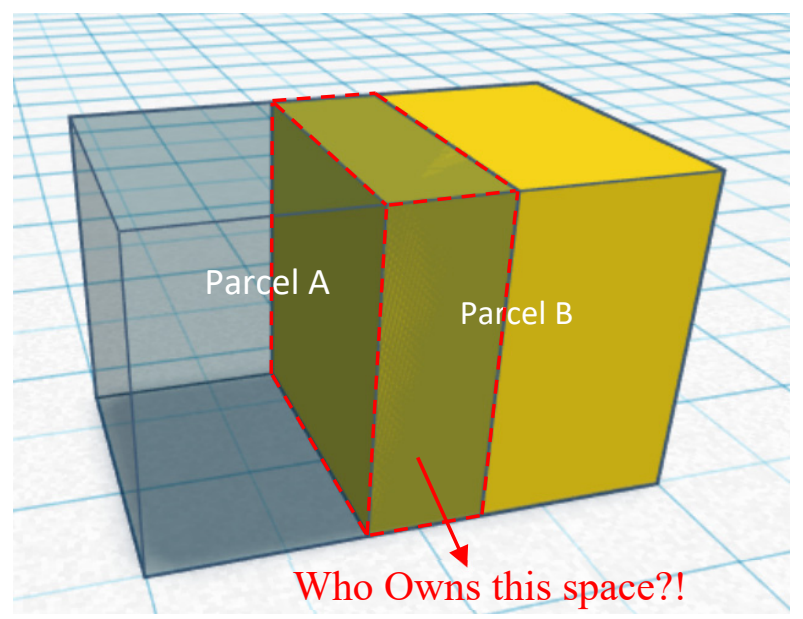

Figure 26 Collision between two 3D objects 


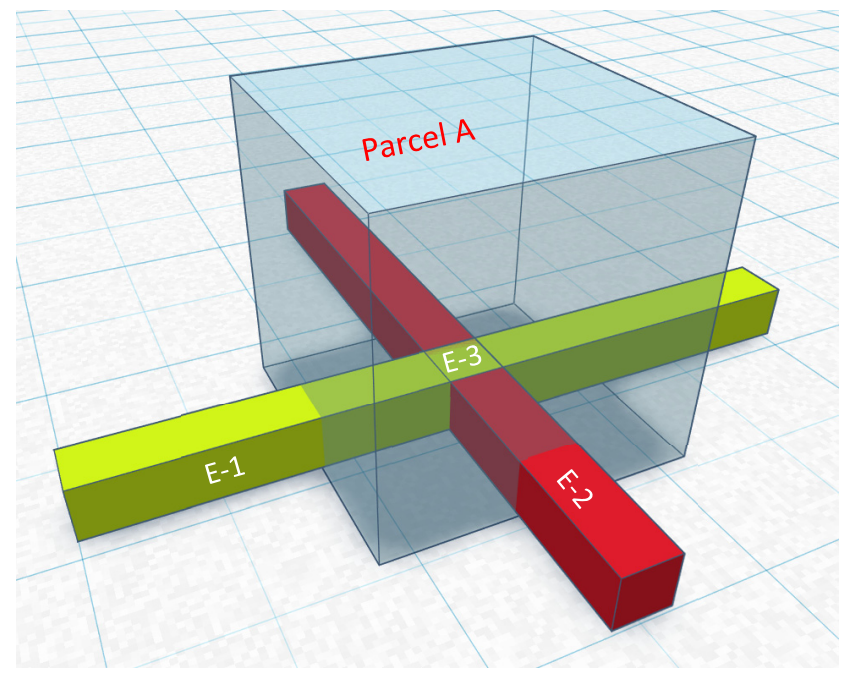

Figure 27 An example of acceptable collision in $3 D$ RRRs

\section{Discussion}

A 3D digital cadastre can smooth the registration process, save time and cost, transparent land transactions and improve the use and management of land (Shojaei, 2014). The state of Victoria in Australia has been moving towards the implementation of digital cadastre by the introduction of 2D ePlan since 2011. However, for the practical implementation of a 3D digital cadastre, principles and validation rules need to be developed based on a structured framework following each jurisdiction and compatible with the nature of 3D geospatial data. This study aimed to propose a structured framework for 3D cadastral data validation within given legislation. According to this framework, checking the validity of 3D digital cadastral data can be considered from three examination aspects: a) Regulatory checks, b) Internal spatial consistency checks, and c) External spatial consistency checks. This proposed framework can establish a foundation for the practical implementation of a 3D validation phase in 3D digital cadastre. However, institutional and legislative frameworks, that provide the legal mandate for the administrative operation of the cadastral system will need to be reviewed to ensure adequate provision for a $3 \mathrm{D}$ digital representation.

3D models effectively facilitate communicating the information of a plan represented by notations. For example, the accurate interpretation and reading information of ownership boundaries through notations are challenging in 2D and 3D plans. However, as can be seen in Figure 28, the digital data environment of 3D models can more effectively communicate boundaries as it provides a $3 \mathrm{D}$ visual representation and structural information (Atazadeh et al., 2017). 


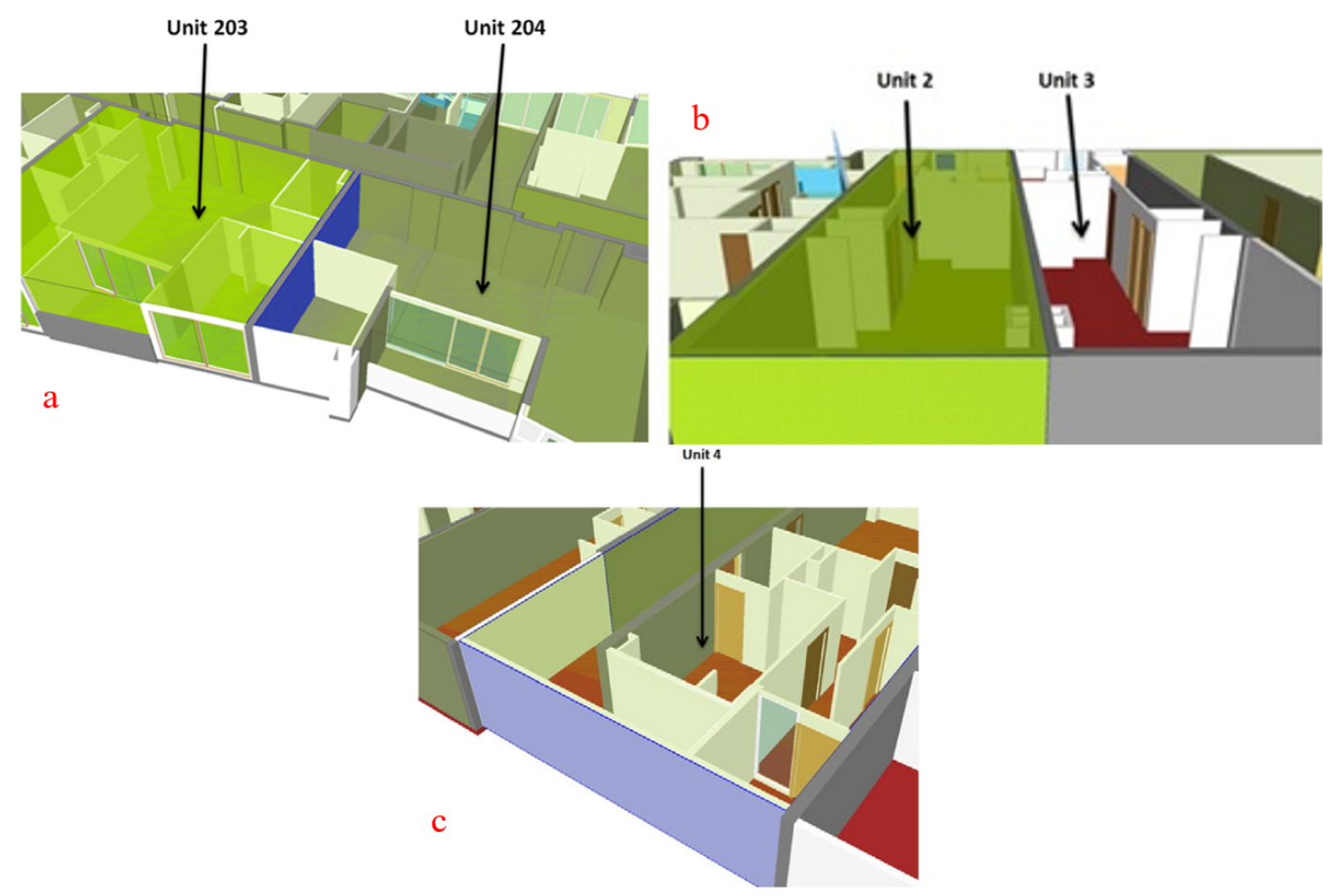

Figure 28 3D visual representation of building boundaries, a) Interior boundary, b) Median boundary, c) Exterior boundary (Source: (Behnam Atazadeh et al., 2017))

The practical implementation of regulatory checks in 3D using 3D geospatial information models need an investigation on policies and legislation in each jurisdiction. The questions like how 3D models are created for existing buildings and new developments, how this administrative information can be embedded into 3D models and how 3D models can be examined through regulatory checks need to be answered for the practical implementation.

The internal spatial consistency checks control legal property objects as single entities. The principles for checking the validity of a single 3D object can be based on a hierarchy method. Since 3D objects are made of nodes, edges and faces, the process can start from these primitives first and then the whole 3D object can be checked through concepts like the watertight concept. However, different ways of modelling property objects, including pure legal, pure physical or an integration of both legal and physical, make different scenarios for developing 3D validation rules. As an example, the concept of watertight to check the 3D misclosure would be entirely different for legal and physical representations (Figure 20). Before checking the watertight concept for 3D objects, we need to assure that their faces are planar. One method for checking the planarity is to fit a plane with a least-square adjustment. The distance between every point forming a face, and this fitted plane should be less than a given tolerance (e.g., $1 \mathrm{~mm}$ )(Ledoux, 2016). It is also important to notice the nodes duplication when a face is created. The combination of such validation rules assures $3 \mathrm{D}$ objects are correctly modelled with no topological issues in the $3 \mathrm{D}$ cadastral data.

After making sure that a single 3D object is topologically valid data, the external spatial consistency needs to be checked. 3D digital cadastral data includes 3D objects representing both primary parcels and secondary interests. The relationship between these objects as well as their spatial position needs to be considered through the process of data validation. However, as discussed, the method of applying validation rules in practice depends on how $3 \mathrm{D}$ volumetric objects are created. The structure chosen will rely on the view taken in this regard and can be affected by regulations and policies in each jurisdiction. For example, the primary parcel connection can be checked only based on the base parcel if we assure that the 3D volumetric object is exactly inside this parcel. However, for checking the intersection between 3D parcels, they need to be excised from an existing 3D column. To check any 
clash between 3D objects representing primary parcels (Figure 28), one method is to triangulate 3D objects, and through an accurate algorithm developed by (Möller, 1997), any clash can be detected (Shojaei et al., 2017).

An automated validation service is one of the fundamental steps towards a comprehensive modernised land administration and 3D digital cadastre, which is one of the objectives of the ICSM Cadastre 2034 Strategy. The concepts and validation rules of this structured framework can facilitate developing a prototype for 3D cadastral data validation. This research will result in a beneficial implementation of 3D examination and validation of multi-level property in Victoria, Australia and, from an international standpoint, this is also a significant step forward.

\section{Conclusions and future work}

This paper has provided an overall insight into the validation requirements for $3 \mathrm{D}$ digital plans specifically for the Victorian jurisdiction. A set of principles and validation rules within this structured framework has been proposed for application to single 3D objects, to the position and relationship of objects on a single digital plan, and to objects that are independently defined on separate plans. This study proposes a framework for 3D validation based on the Victorian jurisdiction with international standpoints in several locations in the paper. However, the actual implementation of this framework will always rely on the characteristics of current policy and legislation of land administration in a certain jurisdiction. Besides, due to the variety of scenarios seen in the real world, the proposed framework and its principles may experience modification to support more possible cadastral situations. During this research, the following issues have been extracted that need to be intended in further studies:

1. What geometric form or 3D model should be used for the implementation phase?

2. How are curved surfaces in cadastral data supposed to be handled?

3. What validation rules can be added for internal and external spatial consistency checks?

4. Which validation rules can be automated?

5. How much can the institutional and legislative policy be flexible to adopt this structured framework?

6. How can this framework be adapted with the cadastral requirements of other countries?

Careful attention to these questions is considered essential for the practical implementation of any framework for 3D cadastral data validation. Further research should be completed to investigate the development of appropriate 3D geometries to represent the wide range of cadastral objects; to further develop and refine the 3D principles and validation rules embedded in each jurisdiction; and the integration of both physical and legal spaces. Another suggested future work is to develop a prototype for the implementation of $3 \mathrm{D}$ validation rules for the internal spatial consistency checks.

\section{Acknowledgements}

This research was supported by Australian Research Council (ARC) [grant number LP160100292]. The authors acknowledge the support of project partners: Land Use Victoria, Intergovernmental Committee on Surveying and Mapping (ICSM) and City of Melbourne. The first author would also like to extend his thanks to Dr. Behnam Atazadeh, Mr. Brian Marwick and Mr. Anthony Campbell, who offered their time and support throughout this research. The authors emphasise that the views expressed in this article are the authors' alone.

\section{ORCID}

Ali Asghari https://orcid.org/0000-0001-8762-2803

Mohsen Kalantari https://orcid.org/0000-0002-6650-5218

Abbas Rajabifard http://orcid.org/0000-0002-4256-3173 
This is a preprint version of the article which has been published in the Journal of Land Use Policy. DOI: https://doi.org/10.1016/j.landusepol.2019.104359

\section{References}

AIEN, A., KALANTARI, M., RAJABIFARD, A., WILLIAMSON, I. \& SHOJAEI, D. Developing and testing a 3D cadastral data model: A case study in Australia. 2012. ISPRS.

AIEN, A., RAJABIFARD, A., KALANTARI, M., WILLIAMSON, I. \& SHOJAEI, D. 2014. Development of XML schemas for implementation of a 3D cadastral data model. 4th International Workshop on 3D Cadastres, Page 131-158.

ATAZADEH, B. 2017. Building information modelling for urban land administration.

ATAZADEH, B. \& KALANTARI, M. 2016. Comparing three types of BIM-Based Models for managing 3D ownership interests in multi-level buildings.

ATAZADEH, B., KALANTARI, M., RAJABIFARD, A. \& HO, S. 2017. Modelling building ownership boundaries within BIM environment: A case study in Victoria, Australia. Computers, Environment and Urban Systems, 61, 24-38.

BRUGMAN, B., TIJSSEN, T. \& VAN OOSTEROM, P. 2011. Validating a 3D topological structure of a 3D space partition. Advancing Geoinformation Science for a Changing World.

CUMERFORD, N. The ICSM ePlan protocol, its development, evolution and implementation. FIG Congress, 2010. 11-16.

DALRYMPLE, K., WILLIAMSON, I. \& WALLACE, J. 2003. Cadastral systems within Australia. Australian surveyor, 48, 37-49.

ERICSON, C. 2004. Real-time collision detection, CRC Press.

ERIKSSON, G. \& JANSSON, L. Strata titles are introduced in Sweden. Proceedings of the XXIV International FIG Congress, Sydney, Australia, 2010. 11-16.

FU, L., YIN, P., LI, G., SHI, Z., LIU, Y. \& ZHANG, J. 2018. Characteristics and Classification of Topological Spatial Relations in 3-D Cadasters. Information, 9.

GRÖGER, G. \& PLÜMER, L. 2011. How to achieve consistency for 3D city models. Geolnformatica, 15, 137-165.

GUO, R., LI, L., YING, S., LUO, P., HE, B. \& JIANG, R. 2013. Developing a 3D cadastre for the administration of urban land use: A case study of Shenzhen, China. Computers, Environment and Urban Systems, 40, 46-55.

JALJOLIE, R., VAN OOSTEROM, P. \& DALYOT, S. 2018. Spatial Data Structure and Functionalities for 3D Land Management System Implementation: Israel Case Study. ISPRS International Journal of Geo-Information, 7.

KARKI, S., MCDOUGALL, K. \& THOMPSON, R. An overview of 3D Cadastre from a physical land parcel and a legal property object perspective. Proceedings of the 24th International Federation of Surveyors International Congress (FIG 2010), 2010a. International Federation of Surveyors (FIG), 1-13.

KARKI, S., THOMPSON, R. \& MCDOUGALL, K. 2010b. Data validation in 3D cadastre. Developments in 3D geo-information sciences. Springer.

KARKI, S., THOMPSON, R. \& MCDOUGALL, K. 2013. Development of validation rules to support digital lodgement of 3D cadastral plans. Computers, Environment and Urban Systems, 40, 34-45.

KAZAR, B. M., KOTHURI, R., VAN OOSTEROM, P. \& RAVADA, S. 2008. On valid and invalid threedimensional geometries. Advances in 3D geoinformation systems. Springer.

LEDOUX, H., WAGNER, DETLEV 2016. OGC CityGML Quality Interoperability Experiment.

MÖLLER, T. 1997. A fast triangle-triangle intersection test. Journal of graphics tools, 2, 25-30.

OOSTEROM, R. T. A. P. V. 2012. Validity of Mixed 2D and 3D Cadastral Parcels in the Land Administration Domain Model.pdf.

RAJABIFARD, A., ATAZADEH, B. \& KALANTARI, M. 2018. A critical evaluation of 3D spatial information models for managing legal arrangements of multi-owned developments in Victoria, Australia. International Journal of Geographical Information Science, 32, 2098-2122.

RENZHONG, G., SHEN, Y., LIN, L. \& PING, L. A multi-jurisdiction case study of 3D cadastre in Shenzhen, China as experiment using the LADM. 2011.

SHOJAEI, D. 2014. 3D cadastral visualisation: understanding users' requirements. 
This is a preprint version of the article which has been published in the Journal of Land Use Policy. DOI: https://doi.org/10.1016/j.landusepol.2019.104359

SHOJAEI, D., OLFAT, H., QUINONES FAUNDEZ, S. I., KALANTARI, M., RAJABIFARD, A. \& BRIFFA, M. 2017. Geometrical data validation in 3D digital cadastre - A case study for Victoria, Australia. Land Use Policy, 68, 638-648.

STOTER, J., PLOEGER, H. \& VAN OOSTEROM, P. 2013. 3D cadastre in the Netherlands: Developments and international applicability. Computers, Environment and Urban Systems, 40, 56-67.

STOTER, J. \& SALZMANN, M. 2003. Towards a 3D cadastre: where do cadastral needs and technical possibilities meet? Computers, Environment and Urban Systems, 27, 395-410.

STOTER, J. E. \& VAN OOSTEROM, P. 2006. 3D cadastre in an international context: legal, organizational, and technological aspects, Crc Press.

STOTER, J. E. \& VAN OOSTEROM, P. J. M. 2005. Technological aspects of a full 3D cadastral registration. International Journal of Geographical Information Science, 19, 669-696.

SUBDIVISION (PROCEDURES) REGULATIONS 2000. 101/2000, The Government of Victoria, 2000.

SUBDIVISION (REGISTRAR'S REQUIREMENTS) REGULATIONS 2011. 111/2011, The Governor in Council, 2011.

SURVEYING (CADASTRAL SURVEYS) REGULATIONS 2005. Surveying (Cadastral Surveys) Regulations 2005.

THOMPSON, R. \& VAN OOSTEROM, P. 2011a. Axiomatic definition of valid 3D parcels, potentially in a space partition.

THOMPSON, R. \& VAN OOSTEROM, P. 2011b. Modelling and validation of 3D cadastral objects. Urban and Regional Data Management.

THOMPSON, R. \& VAN OOSTEROM, P. 2012. Validity of mixed 2D and 3D cadastral parcels in the land administration domain model.

TOMS, K., GRANT, D. \& WILLIAMSON, I. 1986. The south Australian cadastral system. Australian surveyor, 33, 92-104.

VICTORIAN GOVERNMENT 2011. Subdivision Act 1988,

WAGNER, D., WEWETZER, M., BOGDAHN, J., ALAM, N., PRIES, M. \& COORS, V. 2013. Geometricsemantical consistency validation of CityGML models. Progress and new trends in $3 D$ geoinformation sciences. Springer.

ZHANG, C. \& CHEN, T. Efficient feature extraction for 2D/3D objects in mesh representation. Image Processing, 2001. Proceedings. 2001 International Conference on, 2001. IEEE, 935-938.

ZHAO, Z., GUO, R., LI, L. \& YING, S. Topological relationship identification in 3D cadastre. Proceedings of the 3rd International Workshop on 3D Cadastres: Developments and Practices, Shenzhen, China, 2012. 25-26. 


\section{University Library}

\section{- M M N E R VA A gateway to Melbourne's research publications}

Minerva Access is the Institutional Repository of The University of Melbourne

Author/s:

Asghari, A;Kalantari, M;Rajabifard, A

Title:

A structured framework for 3D cadastral data validation - a case study for Victoria, Australia

Date:

2020-11-01

Citation:

Asghari, A., Kalantari, M. \& Rajabifard, A. (2020). A structured framework for 3D cadastral data validation - a case study for Victoria, Australia. Land Use Policy, 98, https:// doi.org/10.1016/j.landusepol.2019.104359.

Persistent Link:

http://hdl.handle.net/11343/247737 